\title{
Regulation of ATP-ubiquitin-dependent proteolysis in muscle wasting
}

\author{
D Attaix, D Taillandier, S Temparis, D Larbaud, \\ E Aurousseau, L Combaret, L Voisin
}

\begin{abstract}
INRA-Theix, Centre de Recherche en Nutrition Humaine de Clermont-Ferrand, 63122 Saint Genès-Champanelle, France
\end{abstract}

Summary - Protein breakdown plays a major role in muscle growth and atrophy. However, the regulation of muscle proteolysis by nutritional, hormonal and mechanical factors remains poorly understood. In this review, the methods available to study skeletal muscle protein breakdown, and our current understanding of the role of 3 major proteolytic systems that are well characterized in this tissue (ie the lysosomal, $\mathrm{Ca}^{2+-d e p e n d e n t ~ a n d ~ A T P-u b i q u i t i n-d e p e n d e n t ~ p r o t e o l y t i c ~ p a t h w a y s) ~ a r e ~ c r i t i c a l l y ~ a n a-~}$ lyzed. ATP-ubiquitin-dependent proteolysis is discussed in particular since recent data strongly suggest that this pathway may be responsible for the loss of myofibrillar proteins in many muscle-wasting conditions in rodents. In striking contrast to either the lysosomal or the $\mathrm{Ca}^{2+}$-dependent processes, ATP-ubiquitin-dependent protein breakdown is systematically influenced by nutritional manipulation (fasting and dietary protein deficiency), muscle activity and disuse (denervation atrophy and simulated weightlessness), as well as pathological conditions (sepsis, cancer, trauma and acidosis). The hormonal control of this pathway, its possible substrates, rate-limiting step, and functional associations with other proteolytic systems are discussed.

\section{skeletal muscle / protein breakdown / ubiquitin / proteasome}

Résumé - Régulation de la protéolyse musculaire ATP-ubiquitine-dépendante au cours des états cataboliques. La protéolyse joue un rôle majeur dans le contrôle de la croissance ou de l'atrophie musculaire. Cependant, ses mécanismes de régulation par les nutriments, les facteurs hormonaux ou l'activité musculaire sont encore peu connus. Cette revue analyse de façon critique les différentes techniques disponibles pour étudier la dégradation des protéines musculaires, et le rôle des 3 systèmes protéolytiques majeurs bien caractérisés dans ce tissu, c'est-à-dire la voie lysosomale, Ca ${ }^{2+}$-dépendante et ATP-ubiquitine-dépendante. La protéolyse ATP-ubiquitine-dépendante est plus particulièrement évoquée, car des travaux récents suggèrent que cette voie serait responsable de la dégradation des protéines contractiles majeures au cours de multiples états cataboliques chez les rongeurs. Contrairement aux systèmes protéolytiques lysosomal et $\mathrm{Ca}^{2+}$-dépendant, la protéolyse ATP-ubiquitinedépendante est systématiquement influencée par les manipulations nutritionnelles (jeûne, régime déficient en protéines), l'activité et l'inactivité musculaire (dénervation, apesanteur simulée), et de nombreux états pathologiques (infections, cancers, traumatismes, acidose). La régulation hormonale, les substrats possibles, l'étape limitante et la coordination fonctionnelle de cette voie de la protéolyse avec les autres systèmes protéolytiques sont discutés. 


\section{INTRODUCTION}

Proteins in skeletal muscle, as in other mammalian tissues, undergo a continuous process of degradation and resynthesis (Waterlow et al, 1978). Rates of protein turnover regulate the levels of specific muscle proteins. In addition, changes in skeletal muscle protein mass during growth and atrophy depend on the overall balance between rates of protein synthesis and breakdown. For example, increased proteolysis contributes to the muscle atrophy seen with starvation and many pathological states (eg, sepsis, trauma, and cancer). However, despite its importance in growth and human disease, the regulation of muscle proteolysis by nutritional, hormonal and mechanical factors remains poorly understood (Kettelhut et al, 1988; Sugden and Fuller, 1991; Tawa and Goldberg, 1994). The purpose of this review is: (i) to outline the limitations of the in vivo and in vitro methods that are used to study muscle protein breakdown; (ii) to analyse the role of the major proteolytic pathways; and (iii) to discuss the regulation of the ATP-ubiquitin-dependent proteolytic process, which is presumably involved in the breakdown of contractile components.

\section{METHODS FOR MEASURING SKELETAL MUSCLE PROTEIN BREAKDOWN}

Studying skeletal muscle proteolysis is difficult because myofibrillar proteins represent approximately $60-70 \%$ of the proteins and turn over rather slowly under normal conditions (Waterlow et al, 1978). Even in severe catabolic conditions, measured changes in protein turnover are difficult to quantify reliably and affect muscle protein mass relatively slowly.

\section{In vivo methods}

In vivo measurements of skeletal muscle protein breakdown are indirect and provide little if any information on intracellular regulatory mechanisms. In young, growing rodents the average rate of protein breakdown is often calculated as the difference between the rate of protein synthesis and the rate of protein deposition (or loss) in a given muscle (Waterlow et al, 1978). Such estimations are imprecise because the rate of protein deposition must be estimated over several days; the rate of protein synthesis is measured within a few minutes or hours following the administration of a labeled amino acid. However, rates of protein deposition and synthesis are not necessarily constant over the period of measurement.

Another method is based on the loss of radioactivity from prelabeled proteins. Amino-acid reutilization, however, results in artificially low rates of protein breakdown (Waterlow et al, 1978).

A third widely used technique is the measurement of urinary 3-methylhistidine excretion. 3-Methylhistidine is formed by a posttranslational methylation of specific histidine residues in actin (and also in myosin heavy chains of fast-twitch skeletal muscles). This amino acid is neither reutilized for protein synthesis nor significantly metabolized, and is quantitatively excreted in urine in rats and humans (Young and Munro, 1978). Therefore, the urinary excretion of 3-methylhistidine provides an index of myofibrillar protein breakdown. However, the visceral muscles of the gastrointestinal tract and some other tissues (eg, skin) contain significant amounts of actin. These tissues contribute disproportionately for their size to 3methylhistidine excretion, because of their rapid rates of protein turnover (Wassner and $\mathrm{Li}, 1982)$. In addition, changes in renal clearance of 3-methylhistidine may complicate the interpretation of such experiments. Con- 
sequently, the use of 3-methylhistidine excretion as a valid and specific index of skeletal muscle protein breakdown is still controversial (Millward et al, 1980; Wassner and $L i$, 1982).

A fourth method involves selective catheterization of an artery and a vein draining a muscle bed, and is based on the isotopic dilution of infused $\left[{ }^{3} \mathrm{H}\right]$ phenylalanine, an amino acid that is not significantly degraded or synthesized in muscle. An index of both the rates of protein breakdown and synthesis is calculated by measuring blood flow as well as the phenylalanine concentration and specific radioactivity in arterial and venous blood (Barrett and Gelfand, 1989). Although particularly useful in humans (or in large animal species), this method provides only a minimal estimate of the rate of protein breakdown because of the reutilization of the label.

Finally, another approach based on the measurements of mRNA levels for proteases or proteins involved in proteolysis has been developed in the past few years (Medina et al, 1991; Attaix, 1993; Wing and Goldberg, 1993). These mRNA levels increased in skeletal muscle in many catabolic conditions, and may provide information about specific proteases or proteolytic pathways activated in muscle-wasting conditions, as described in detail below. However, the significance of variation in mRNA levels for almost all proteases is still totally unclear. mRNA levels do not necessarily reflect protein levels or protease activity. For example, Ilian and Forsberg (1992) reported increased mRNA levels for $\mu$ - and m-calpains in muscles from fasted rabbits, but no variation in protease activities. Changes in either the rate of protease turnover or in endogenous protease inhibitors levels or activity may explain discrepancies between levels of protease mRNA and actual protease activity. Therefore, this approach is useful when combined with other techniques such as in vitro meth- ods and/or measurements of protease activities, but its theoretical limitations must be kept clearly in mind.

\section{In vitro methods}

In vitro muscle preparations have been widely used to study protein breakdown. Most studies employ thin muscles incubated in vitro. The slow-twitch oxidative soleus, the fast-twitch glycolytic extensor digitorum longus or the diaphragm muscle from young rats $(<80 \mathrm{~g})$ or mice, and the epithrochlearis muscle from adult and old rats have been extensively used. Alternatively, the hindlimbs and hindquarters of rats have been perfused (see Kettelhut et al, 1988 for a review). Net tyrosine or phenylalanine release in the medium or the perfusate reflects the absolute rate of protein breakdown under conditions where protein synthesis is blocked by cycloheximide, since neither amino acid is significantly metabolized in muscle. Tyrosine release is widely used because it is easily measured fluorometrically. Alternatively, absolute rates of protein breakdown can be obtained from simultaneous measurements of net tyrosine release and of protein synthesis within the same preparation. The rate of protein synthesis is measured by following the incorporation of $\left[{ }^{14} \mathrm{C}\right]$ phenylalanine, corrected by the average Tyr/Phe ratio in muscle proteins. The absolute rate of protein breakdown is then calculated by adding the net tyrosine release to the rate of tyrosine incorporation into proteins (Tischler et al, 1982). Rates of tyrosine release reflect the breakdown of all classes of proteins. Approaches have been developed to estimate the breakdown of myofibrillar proteins (eg, actin and some myosins) by following the rate of 3-methylhistidine release (Lowell et al, 1986).

It should be pointed out that muscle preparations are always in a catabolic state. Therefore, observations in vitro may not necessarily reflect the in vivo situation, and 
caution must be exercised in interpreting such data. On the other hand, if incubated muscles are catabolic, this is in large part due to abnormally low rates of protein synthesis, and not just to elevated proteolysis. Furthermore, muscle preparations are highly responsive to nutrient and hormone supply as occurs in vivo. Many groups using isolated muscles incubated in the less possible negative conditions of nitrogen balance (with oxygen supply, tension, insulin and amino acids, especially the branched-chain residues) have reported variations in both rates of protein synthesis and breakdown that generally closely mimic observations reported in intact animals. Finally, this approach is particularly important, since incubated muscles are the only system where selective inhibition may be used to identify the contribution of different proteolytic systems to overall skeletal muscle protein breakdown (see below).

\section{PROTEOLYTIC PATHWAYS IN MUSCLE}

\section{Major proteolytic systems}

Like other mammalian tissues, skeletal muscle contains multiple proteolytic systems that are presumably responsible for the breakdown of specific proteins, although this is probably a gross oversimplification.

The best known proteolytic system is the lysosomal pathway. Lysosomes are particularly abundant in the liver, and 2 lysosomal vacuolar processes (macro and microautophagy) play a major role in the degradation of hepatic long-lived proteins (Mortimore et al, 1992). By contrast, skeletal muscle contains few lysosomes. Several observations suggest that the major lysosomal proteases (cathepsins $B, H, L$ and D) do not contribute significantly to overall protein breakdown in muscles incubated under optimal conditions (eg, with tension and in the presence of insulin and amino acids) (Furuno et al, 1990; Wing and Goldberg, 1993; Taillandier et al, 1994; Temparis et al, 1994). In addition, lysosomes are not involved in the degradation of myofibrillar proteins (Lowell et al, 1986; Furuno et al, 1990). Increased cathepsin activities have been reported in some instances of muscle wasting (eg, cathepsin $B$ during denervation atrophy; Furuno et al, 1990). By contrast, in starvation, cathepsin $B, H$ and $L$ activities actually fell below the values obtained in fed rats (Belkhou et al, 1994). Cathepsin B or B $+L$ activities were also unchanged in the atrophying muscles of rats bearing a Yoshida sarcoma (Temparis et al, 1994). A small (16\%) and transient increase in cathepsin $\mathrm{H}$ activity, but no change or decreased cathepsin $\mathrm{B}$ and $\mathrm{B}+\mathrm{L}$ activities, were recently observed in muscle during the progressive cachexia induced in rats by the Yoshida $\mathrm{AH}-130$ ascites hepatoma (Llovera et al, 1994). Gene expression of cathepsins is also not systematically modified in several muscle-wasting conditions. We recently found no variation in cathepsin D mRNA level in septic rats (Voisin et al, 1994), or in cathepsin B mRNA level in tumor-bearing animals (Temparis et al, 1994). By contrast, Taillandier et al (1994) observed significant increases in mRNA levels for cathepsins $B, L$ and $D$ in the soleus muscle of hindlimb suspended rats. Ilian and Forsberg (1992) also recently reported a large increase in cathepsin D expression in fasted rabbits. Lysosomal proteolysis is widely believed to be non-selective. However, experiments by Dice and coworkers demonstrated that a $70 \mathrm{kDa}$ heat shock protein binds to peptide sequences related to KFERQ (Lys-Phe-Glu-Arg-GIn) that specifically target proteins for lysosomal degradation (Chiang et al, 1989). Proteins containing KFERQ sequences were selectively depleted in the liver and heart but not skeletal muscle of fasted rats, suggesting again that lysosomal proteolysis 
plays a minor role in muscle-protein breakdown (Wing et al, 1991).

The best characterized nonlysosomal proteases are two $\mathrm{Ca}^{2+}$-dependent enzymes, $\mu$-calpain and m-calpain, which differ in their affinities for $\mathrm{Ca}^{2+}$ (Goll et al, 1992). The $\mathrm{Ca}^{2+}$-dependent proteolytic process does not appear to contribute significantly to overall proteolysis in muscles from normal animals incubated under tension (Wing and Goldberg, 1993; Taillandier et al, 1994; Tawa and Goldberg, 1994; Temparis et al, 1994). The contribution of $\mathrm{Ca}^{2+}$ dependent proteolysis to overall protein breakdown remains small in stretched incubated muscles from fasted (Wing and Goldberg, 1993), non-weight bearing (Taillandier et al, 1994), and tumor-bearing (Temparis et al, 1994) rats. There are few biological models in which significant changes in calpain activities occur (Ilian and Forsberg, 1992). Furthermore, an activation of $\mathrm{Ca}^{2+}$-dependent proteolysis in tumor-bearing (Baracos et al, 1992) and fasted (Wing and Goldberg, 1993) rats seems very unlikely. Evidence that calpains may initiate myofibrillar protein breakdown was presented by Goll et al (1992). However, inhibitors of calpains do not affect myofibrillar protein breakdown in vitro (Lowell et al, 1986; Kettelhut et al, 1988). Transcription of genes encoding calpains may be increased in skeletal muscles of fasted rabbits (llian and Forsberg, 1992), and $\mathrm{mRNA}$ levels for $\mathrm{m}$-calpain increased in several catabolic conditions (eg, sepsis, Voisin et al, 1994; cancer, Temparis et al, 1994; and simulated weightlessness, Taillandier et al, 1994). Enhanced expression of $\mathrm{m}$-calpain was correlated with increased activity in non-weight-bearing rats (Taillandier, 1993), but not in fasted rabbits (llian and Forsberg, 1992). In fact, there is now growing evidence that calpains do not play a major role in general intracellular protein turnover, but are involved in limited proteolysis of some specific target proteins, eg, processing of protein kinase $C$ (Johnson,
1990; Melloni and Pontremoli, 1991). Many short-lived proteins contain PEST (Pro, Glu, Ser, Thr) sequences (Rogers et al, 1986). Such sequences, very negatively charged, may bind $\mathrm{Ca}^{2+}$, and this increased local $\mathrm{Ca}^{2+}$ concentration may activate calpains. Recent evidence suggests that the insulin receptor substrate (IRS-1) is a PEST protein susceptible to calpain degradation in vitro (Smith et al, 1993). A third calpain, p94, which is expressed abundantly only in skeletal muscle, has been recently isolated, and its gene cloned and sequenced (Sorimachi and Suzuki, 1992). However its role and physiological importance are still unknown.

Fagan et al (1987) demonstrated that skeletal muscle also contains a soluble ATP-ubiquitin-dependent proteolytic system, that is widely believed to catalyze the selective breakdown of short-lived and abnormal proteins (Rechsteiner, 1991). Ubiquitin (a 76-amino-acid protein highly conserved present in all eukaryotes) is first activated in an ATP-dependent fashion and then covalently binds to protein substrates via an isopeptide bond between the $C$ terminal residue of ubiquitin and $\varepsilon$-amino groups of lysine residues of proteins (see Finley and Chau, 1991; Hershko and Ciechanover, 1992; Jentsch, 1992 for recent reviews). Ubiquitination of proteins always requires the ubiquitin-activating enzyme, $E_{1}$, and one of the ubiquitin carrier proteins, $E_{2} s$, to generate the first attachment of a single ubiquitin moiety to a substrate. Some conjugation reactions also require a third enzyme, known as ubiquitin protein ligases, $\mathrm{E}_{3} \mathrm{~s}$, for substrate recognition. Multiubiquitination of the substrate is always observed in $E_{3}$-dependent reactions; but also occurs in some $\mathrm{E}_{3}$-independent reactions. The $14 \mathrm{kDa}$ $E_{2}$ species is one of the mammalian $E_{2} s$ that best supports $E_{3}$-dependent conjugate formation and protein breakdown (Hershko and Ciechanover, 1992; Wing and Banville, 1994). Substrates can be multiubiquitinated by the attachment of ubiquitin chains or 
trees. While ubiquitination is clearly dependent on the $\mathrm{N}$-terminal amino-acid residue of some substrates (reviewed by Varshavsky, 1992), many proteins degraded by the ubiquitin system are recognized by different signals (Hershko and Ciechanover, 1992). Polyubiquitinated proteins are preferentially degraded by a very large 1500 $\mathrm{kDa}(26 \mathrm{~S})$ proteolytic complex that requires ATP for activation and substrate hydrolysis (Goldberg, 1992; Hershko and Ciechanover, 1992). The $26 \mathrm{~S}$ complex contains the 20 $S$ proteasome with proteolytic function (reviewed by Hoffman et al, 1992), and multiple other components. Although the $20 \mathrm{~S}$ proteasome has been shown to be an essential component of the ATP-ubiquitindependent proteolytic pathway (Hoffman et al, 1992), skeletal muscle proteasome can degrade proteins in an ATP-dependent process that does not require ubiquitin (Driscoll and Goldberg, 1989). The $20 \mathrm{~S}$ proteasome (also called multicatalytic proteinase complex, high-molecular-weight protease or prosome) constitutes up to $1 \%$ of the soluble proteins in eukaryotic cells (Tanaka et al, 1986). This cylindrical particle is organized as a stack of 4 rings of 6 (Orlowski, 1990) or 7 (Rivett, 1993) subunits and exists in both the cytoplasm and the nucleus. The rat-liver proteasome contains 13-15 subunits with molecular masses of 21 to $31 \mathrm{kDa}$ (Tanaka et al, 1992), but up to 25 different subunits have been identified in eukaryotes (Rivett, 1993). Proteasomes contain at least 5 types of endopeptidase activities (Orlowski, 1990; Rivett, 1993). The genes of multiple proteasome subunits have been cloned and sequenced from rat and humans (reviewed by Tanaka et al, 1992). No region in their predicted amino-acid sequences was found to be homologous to the primary structure of the active sites in other known proteases, suggesting that proteasomes may correspond to a novel class of proteolytic enzymes. However, it has been recently suggested that the rat proteasome subunit RC10-Il was necessary for the expression of trypsin-like catalytic activity (Nishimura et al, 1993).

As described in detail below, multiple observations indicate that the ATP-ubiquitin-dependent proteolytic process plays a major role in skeletal muscle-protein breakdown.

\section{Estimation of the contribution of different proteolytic pathways to overall protein breakdown}

Rates of protein degradation attributable to different proteases or proteolytic systems must be measured in an unambiguous way. Incubated muscles offer unique advantages to study the regulation of a given proteolytic pathway. Inhibitors of either lysosomal acidification ( $\mathrm{eg}$, methylamine, chloroquine, and propylamine) or function (eg, E64 and leupeptin, which inhibit the cysteine proteases cathepsins $B, H$ and $L$ ) have been used to estimate the contribution of the lysosomal proteolytic process to overall rates of protein breakdown. E64 and leupeptin also inhibit the calpains, as well as a $\mathrm{Ca}^{2+}$-free medium. More recently, a non-lysosomal

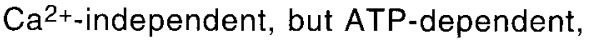
proteolytic process has also been quantified in incubated muscles (Kettelhut et al, 1988; Tawa et al, 1992; Wing and Goldberg, 1993). ATP depletion (up to $95 \%$ ) is performed using 2-deoxyglucose and dinitrophenol that block glycolysis and oxidative phosphorylation, respectively. However, the quantification of the ATP-dependent process must be performed following the inhibition of $\mathrm{Ca}^{2+}$-dependent proteases (by E64 and using a $\mathrm{Ca}^{2+-f r e e ~ m e d i u m), ~}$ because ATP depletion actually stimulates $\mathrm{Ca}^{2+-d e p e n d e n t ~ p r o t e o l y s i s ~(K e t t e l h u t ~ e t ~}$ al, 1988; Fagan et al, 1992). Since E64 inhibits cysteine lysosomal proteases, methylamine is added to the medium to maximally suppress lysosomal proteolysis in such conditions. 
Another approach is based on the stimulation of the lysosomal process (in the absence of insulin and amino acids, which block the formation of autophagic vacuoles) or of $\mathrm{Ca}^{2+}$-dependent proteolysis (in the presence of $\mathrm{Ca}^{2+}$ ionophores in muscles incubated without tension). Such experiments give an estimation of the maximal capacity of the muscles to carry out either lysosomal or $\mathrm{Ca}^{2+-}$-dependent proteolysis in a particular condition.

In conclusion, in vitro preparations are the only system where selective inhibition/activation may be used to identify the contribution of the different proteolytic systems to overall proteolysis. Since the available inhibitors have limitations, other indications of levels or activity of proteolytic systems are a useful adjunct to inhibitor studies. However, measures of protease activity require specific substrates and are confounded by the presence of endogenous inhibitors. In addition, most proteolytic assays utilize artificial and not physiological radiolabeled or peptide substrates. The hydrolysis of such substrates by a given protease may not reflect the in vivo degradation of physiological substrates. Protease activity is also regulated by rates of protease synthesis (to which protease mRNA levels may be related) and protease degradation. Thus, whenever possible, it is highly advisable to combine multiple approaches to elucidate the precise role of any proteolytic process.

\section{REGULATION OF THE ATP-UBIQUITIN- DEPENDENT PROTEOLYTIC SYSTEM IN MUSCLE}

\section{Regulation by nutrients}

Short-term fasting leads to a mobilization of muscle protein, resulting from a decrease in protein synthesis and from an increase in non-myofibrillar and myofibrillar protein breakdown (Li and Goldberg, 1976; Li et al, 1979; Lowell et al, 1986). Increased protein breakdown of non-myofibrillar proteins is presumably mediated by the lysosomal pathway (Lowell et al, 1986; Wing and Goldberg, 1993). The decreased availability of amino acids and the low level of circulating insulin may contribute to increased proteolysis. Both insulin and amino acids inhibit the formation of autophagic vacuoles in liver (Mortimore et al, 1992), and protein breakdown in skeletal muscle (Kettelhut et al, 1988). However, Lowell et al (1986) reported that the large increase in myofibrillar protein breakdown observed in perfused hindquarters of fasted rats does not occur by the lysosomal or the $\mathrm{Ca}^{2+}$-dependent pathways. In these experiments, agents that block lysosomal acidification (chloroquine, $\mathrm{NH}_{4} \mathrm{Cl}$ ) or the autophagic pathway (insulin, amino acids), and an inhibitor of cathepsins $B, H$ and $L$ and calpains (leupeptin) do not affect 3methylhistidine release. The first evidence that the skeletal muscle ATP-ubiquitindependent proteolytic pathway is activated upon starvation was obtained by Goldberg and coworkers (Kettelhut et al, 1988; Medina et al, 1991). Most of the increased proteolysis observed in the muscles from fasted rats was not affected by inhibitors of the lysosomal and $\mathrm{Ca}^{2+}$-dependent pathways. By contrast, incubation of these muscles under conditions where intracellular ATP was depleted almost totally suppressed increased proteolysis due to fasting (Medina et al, 1991; Medina et al, 1992; Wing and Goldberg, 1993). The rise in ATP-dependent proteolysis observed during starvation was associated with increased mRNA levels for ubiquitin (Medina et al, 1991; Medina et al, 1992; Wing and Goldberg, 1993) and the $14 \mathrm{kDa}$ ubiquitin-conjugating enzyme (14 kDa $E_{2}$ ), which mediates the formation of ubiquitinprotein conjugates (Wing and Banville, 1994), accumulation of ubiquitinated pro- 
teins, and increased expression of subunits of the $20 \mathrm{~S}$ proteasome (Medina et al, 1992). Upon refeeding, total and ATPdependent proteolysis, levels of ubiquitin-protein conjugates, and expression of ubiquitin (Medina et al, 1992), $14 \mathrm{kDa} \mathrm{E}_{2}$ (Wing and Banville, 1994), or proteasome subunits (Medina et al, 1992) returned to normal. ATP-ubiquitin-stimulated proteolysis was also enhanced in the soluble extracts of skeletal muscle from fasted rabbits (Medina et al, 1992), in accordance with an increased mRNA level for the C2 proteasome subunit reported by Ilian and Forsberg (1992) in similar conditions.

In young animals fed an inadequate dietary intake both rates of muscle protein synthesis and breakdown fell (Tawa and Goldberg, 1994). In contrast with starvation, these changes in protein turnover appear to preserve muscle mass and protein content. Tawa et al (1992) have shown that the suppression of skeletal muscle-protein breakdown observed in rats fed a proteindeficient diet is accompanied by reduced lysosomal proteolysis. Protein deficiency lowered the levels of many lysosomal proteases (cathepsins B, H, C, and carboxypeptidases $A$ and $C$ ) without any effect on cathepsin D. However, following the inhibition of the lysosomal proteolytic pathway, proteolysis remained lower in protein deficient animals than in control rats. In fact, the reduction in protein breakdown observed in these animals was due to a marked reduction in ATP-dependent proteolysis that explained the fall in overall proteolysis. Accordingly, the muscle content of proteasome fell significantly in animals fed a protein-deficient diet (Tawa and Goldberg, 1994).

Therefore, the stimulation or inhibition of the ATP-ubiquitin-dependent proteolytic pathway following nutritional manipulation is clearly correlated with either muscle protein loss or preservation in starvation and protein deprivation, respectively. ATP-ubiquitin-dependent proteolysis in
experimental models of muscle atrophy

\section{Disuse}

Muscle mass and protein content are extremely sensitive to disuse. In rats, muscle atrophy seen after section of the sciatic nerve results primarily from increased protein breakdown (Furuno et al, 1990). Treatments that maximally activate either the lysosomal or the $\mathrm{Ca}^{2+}$-dependent pathway were more effective in stimulating overall protein breakdown in the denervated muscles than in controls, but did not affect the breakdown of myofibrillar components (Furuno et al, 1990). By contrast, ATP depletion in denervated muscles suppressed the overall increase in total proteolysis and inhibited 3-methylhistidine release by $56 \%$ (Medina et al, 1991). Enhancement of ATPdependent proteolysis observed in atrophying muscles from denervated animals was associated with a rise in mRNA level for polyubiquitin (Medina et al, 1991) and proteasome subunits (Medina et al, 1992), suggesting that this pathway was responsible for the loss of contractile proteins.

Another example of disuse is real or simulated weightlessness. In such conditions, increased protein breakdown is the major determinant of muscle wasting in antigravity muscles, ie the soleus (Thomason and Booth, 1990). Experiments by Goldspink et a/ (1986) suggested an activation of cathepsin D. By contrast, Tischler et al (1990) reported that enhanced proteolysis observed in the soleus muscle from suspended animals occurred by a non-lysosomal mechanism. We have recently found that the lysosomal and $\mathrm{Ca}^{2+}$-dependent proteolysis was greatly enhanced $(254 \%)$ in the soleus muscle of non-weight-bearing rats (Taillandier et al, 1994). Accordingly, we also observed large increases in mRNA levels for lysosomal (cathepsins B, $L$ and D), and $\mathrm{Ca}^{2+}$ 
dependent (m-calpain) proteases. The enhanced expression of $m$-calpain was associated with increased enzyme activity. By contrast, we were unable to detect any change in cathepsin $B$ or $B+L$ activities, as previously reported by Tischler et al (1990). However, the lysosomal and $\mathrm{Ca}^{2+}$ dependent proteolysis did not exceed $18 \%$ of total proteolysis in the atrophying muscles, and the inhibition of both processes did not suppress increased proteolysis in the unweighted soleus. Haas and Riley (1988) previously reported significant alterations in the ubiquitin pools within such muscles. Accordingly, we found large increases in mRNA levels for both ubiquitin and the $14 \mathrm{kDa} E_{2}$ in the soleus muscle of nonweight-bearing rats, as well as increased expression of $\mathrm{C} 2$ and $\mathrm{C} 9$ proteasome subunits (Taillandier et al, 1994).

Therefore, the major proteolytic systems are coordinately activated in skeletal muscle during disuse, although there are presumably some differences in increased lysosomal proteolysis in atrophy induced by denervation or unweighting of rat skeletal muscle (Tischler et al, 1990). However, neither the cathepsins nor the calpains appear to be primarily responsible for muscle wasting.

\section{Pathological conditions}

In many pathological states (eg, sepsis, trauma and cancer) enhanced protein breakdown in skeletal muscle, the major protein reservoir in the body, is a key metabolic adaptation providing the organism with free amino acids for increased gluconeogenesis and direct oxidation. In some instances, for example, in sepsis, net mobilization of muscle protein also provides free amino acids for acute phase protein synthesis in the liver.

Enhanced skeletal muscle proteolysis was observed within 6-7 h after the injection of $E$ coliendotoxin into rats, and was mainly attributable to increased ATP-dependent proteolysis (Attaix and Goldberg, unpublished observations). This adaptation occurred primarily in white muscles (eg, extensor digitorum longus, EDL), but not in the dark soleus. Accordingly, increased mRNA levels for polyubiquitin were observed in EDL or tibialis anterior muscles, but not in the soleus. However, the effects of endotoxin are extremely transient, so that muscle wasting is not apparent. Thus, rates of proteolysis were measured in muscles from rats injected with live $E$ coli (Voisin et al, 1994). Two days after infection, the mass of several leg muscles was approximately $20 \%$ lower in septic rats than in pair-fed controls. Measurements of rates of protein turnover in incubated epitrochlearis muscle of infected animals confirmed that enhanced proteolysis (rather than depressed protein synthesis) was responsible for muscle wasting. mRNA levels for $\mathrm{m}$-calpain, ubiquitin and the C9 proteasome subunit were systematically higher in septic animals than in pair-fed controls, but no change was apparent in cathepsin D expression. Interleukin-1 (IL-1) (Baracos et al, 1983) and tumor necrosis factor- $\alpha$ (TNF$\alpha$ ) (Flores et al, 1989) overproduced by activated macrophages promote muscle catabolism in sepsis. The subcutaneous injection of recombinant IL-1 $\beta$ together with tumor necrosis TNF- $\alpha$ (10 $\mu \mathrm{g}$ of each cytokine/ $100 \mathrm{~g}$ body weight) into rats clearly reproduced the effect of endotoxin on skeletal muscle proteolysis (Attaix and Goldberg, unpublished observations). Both treatments resulted in increased ATP-dependent proteolysis and ubiquitin expression. In addition, pretreatment of rats with either an antiTNF antibody or the receptor antagonist of IL-1 (IL-1 ra) reduced the increased ATPdependent proteolysis observed in endotoxin-treated rats. However, neither IL-1 $\beta$ nor TNF- $\alpha$ alone affected the ATPdependent proteolytic process. Injecting IL-1 $\beta$ alone increased ubiquitin mRNA levels to the same extent as injecting the mix- 
ture of IL-1 $\beta$ and TNF- $\alpha$, but TNF- $\alpha$ alone was ineffective. Since both cytokines were required for the increase in muscle proteolysis, the rise in ubiquitin mRNA by itself did not cause the enhancement of ATP-dependent proteolysis during infection. The 2 cytokines may synergistically signal increased protein breakdown via distinct and indirect mechanisms, since the mixture of cytokines did not affect ATP-dependent proteolysis when added in vitro. In contrast with our observations, Garcia-Martinez et al (1993) recently reported that a single intravenous injection of TNF- $\alpha$ alone (10 $\mu \mathrm{g} / 100 \mathrm{~g}$ body weight) resulted in an accumulation of ubiquitin conjugates in rat skeletal muscle. These discrepant results may reflect differences in the mode of administration of TNF $\alpha$ (ie, intravenous vs subcutaneous).

Skeletal muscle protein wasting is also commonly observed in cancer patients and tumor-bearing animals, and results from impaired protein synthesis and/or enhanced proteolysis (Pisters and Brennan, 1990). In rats bearing a Yoshida sarcoma, muscles close to the tumor underwent atrophy before generalized muscle wasting was apparent (Temparis et al, 1994). This local atrophy resulted from increased protein breakdown, without any significant change in protein synthesis. Incubating the atrophying EDL muscles from tumor-bearing rats in the presence of inhibitors of the lysosomal and the $\mathrm{Ca}^{2+-d e p e n d e n t ~ p r o t e o l y t i c ~ p a t h w a y s ~ d i d ~}$ not suppress the enhanced proteolysis. In contrast, concomitant ATP depletion suppressed the increased protein breakdown. Accordingly, increased expression of ubiquitin, $14 \mathrm{kDa}$ E2 and $\mathrm{C} 8$ or $\mathrm{C} 9$ proteasome subunits was observed in atrophying muscles from tumor-bearing rats (Temparis et al, 1994). A small increase in mRNA level for m-calpain (but not for cathepsin B) was also observed in these muscles, suggesting an activation of both ATP-ubiquitin-dependent and $\mathrm{Ca}^{2+-d e p e n d e n t ~ p r o t e o l y s i s . ~ B a r a c o s ~}$ et al (1992) reported that accelerated proteolysis in muscles of cachectic rats bearing Yoshida ascites hepatoma resulted primarily from activation of ATP-ubiquitin-dependent proteolysis. In addition, these authors reported increased lysosomal protein degradation, but found no evidence for stimulated $\mathrm{Ca}^{2+-d e p e n d e n t ~ p r o t e o l y s i s . ~ A n ~ a c c u m u l a-~}$ tion of ubiquitin-protein conjugates was also recently observed in skeletal muscles of cachectic animals bearing the fast-growing $\mathrm{AH}-130$ Yoshida ascites hepatoma (Llovera et al, 1994). However, Llovera et al (1994) found no evidence for enhanced lysosomal proteolysis, in contrast with the observations by Baracos et al (1992).

Evidence for increased expression of multiple components of the ubiquitin-dependent proteolytic pathway (ubiquitin, $14 \mathrm{kDa}$ $E_{2}$, or proteasome subunits) was also observed in acidotic rats (Mitch et al, 1994) and following trauma (Baracos and Attaix, unpublished observations). Cathepsin B mRNA level did not change in muscle from acidotic rats, but increased ubiquitin mRNA returned to control levels within $24 \mathrm{~h}$ after cessation of acidosis (Mitch et al, 1994).

Taken together these data strongly suggest that the ubiquitin-dependent proteolytic pathway may be responsible for degrading skeletal muscle proteins resulting in the muscle wasting observed in several pathological conditions. Enhanced ATP-ubiquitin-dependent proteolysis is not due to anorexia that often prevails in such conditions. Enhanced ATP-dependent proteolysis occurred in septic (Voisin et al, 1994) and tumor-bearing (Baracos et al, 1992) rats, compared to pair-fed controls.

\section{Regulation by hormones}

Few experiments have been performed to identify the hormonal factors that regulate ATP-dependent proteolysis. Wing and Goldberg (1993) reported that adrenalectomy 
partially prevented the increase in skeletal muscle proteolysis and totally suppressed the increase in ubiquitin mRNA level normally seen in fasted rats. By contrast, injection of dexamethasone restored both responses. Glucocorticoids appeared essential for the activation of the ATP-dependent process, but not for the rise in lysosomal proteolysis in fasting. Glucocorticoids may also be required for increased muscle ATPdependent proteolysis in metabolic acidosis (Mitch et al, 1994). Furthermore, an injection of dexamethasone resulted in increased protein breakdown in epitrochlearis muscle from adult, but not from aged rats (Dardevet et al, 1994). Accordingly, mRNA levels for the $14 \mathrm{kDa} E_{2}$ and proteasome subunits were increased in dexamethasone-treated adult animals, but not in aged rats.

Insulin (Wing and Banville, 1994) and IGF-1 (Wing and Banville, 1992) have been reported to lower mRNA levels for the $14 \mathrm{kDa} \mathrm{E}_{2}$ in rat $\mathrm{L} 6$ myotubes, but the significance of these observations in vivo is unclear. Levels of both insulin and IGF-1 fall with fasting and increase upon refeeding. These variations could be related to increased and decreased $14 \mathrm{kDa} \mathrm{E}_{2}$ expression seen in muscle upon fasting and refeeding, respectively (Wing and Banville, 1994). Finally, there is some evidence that hypothyroidism may result in reduced ATP. dependent proteolysis by altering the content of $26 \mathrm{~S}$ and $20 \mathrm{~S}$ proteasomes in skeletal muscle (Tawa and Goldberg, 1994).

\section{Substrates of ATP-ubiquitin-dependent proteolysis in muscle and the rate limiting step}

The best known substrates of the ubiquitin proteolytic pathway are short-lived or denatured, misfolded, and mislocalized proteins (Rechsteiner, 1991). However, the degradation of skeletal muscle protein by the nonlysosomal ATP-ubiquitin-dependent pro- teolytic pathway appears to be enhanced under many catabolic conditions (fasting, denervation atrophy, simulated weightlessness, sepsis, cancer, metabolic acidosis, and trauma), and is reduced when protein mass is preserved (eg, in protein deficiency) or improved (eg, upon refeeding following starvation). These observations strongly suggest that ATP-ubiquitin-dependent proteolysis plays a major role in myofibrillar protein breakdown. Other lines of evidence support this hypothesis. First, ATP depletion inhibits 3-methylhistidine release in vitro (Kettelhut et al, 1988; Medina et al, 1991; Tawa and Goldberg, 1994), in striking contrast with inhibitors of lysosomal and $\mathrm{Ca}^{2+}$. dependent proteolysis (Lowell et al, 1986; Furuno et al, 1990). Second, the rise in ubiquitin-protein conjugates was recently found in the myofibrillar fraction, suggesting that long-lived contractile proteins could be degraded by this pathway (Tawa and Goldberg, 1994). Third, purified proteasome preparations can degrade myofibrillar proteins in certain conditions (Mykles and Haire, 1991).

There are at least 2 possible rate limiting steps in the ATP-ubiquitin-dependent proteolytic pathway, substrate ubiquitination and/or the degradation of proteins conjugated to ubiquitin. Wing and Banville (1994) suggested that substrate ubiquitination mediated by the $14 \mathrm{kDa} \mathrm{E}_{2}$ may be rate limiting in the pathway. By contrast, the accumulation of ubiquitinated proteins observed in muscles from fasted and denervated (Medina et al, 1992) or tumor-bearing (Llovera et al, 1994) rats suggested that the proteolytic activities of the proteasome could be the rate limiting step. In addition, we have observed increased mRNA levels for both ubiquitin and the $14 \mathrm{kDa} \mathrm{E}_{2}$ in muscles from rats bearing a Yoshida sarcoma for a few days (Temparis et al, 1994). At this stage, muscle wasting did not occur. Accordingly rates of protein breakdown and mRNA levels for $\mathrm{C} 8$ and $\mathrm{C} 9$ proteasome 
subunits in these muscles were not significantly different from control values. In other words, a presumable alteration of substrate ubiquitination did not result in increased proteolysis. An increase in mRNA levels for proteasome subunits was only detectable when muscle wasting was apparent. Although these observations also suggest that substrate ubiquitination is not the rate limiting step in the ATP-ubiquitin-dependent pathway, further experiments are clearly needed to elucidate this point.

\section{Functional associations between proteolytic systems}

A concomitant stimulation of the ATP-ubiquitin-dependent proteolytic pathway with either the $\mathrm{Ca}^{2+}$-dependent (Temparis et al, 1994; Voisin et al, 1994) or the lysosomal process (Baracos et al, 1992; Wing and Goldberg, 1993) or both (Furuno et al, 1990; Ilian and Forsberg, 1992; Taillandier 1993) seems to prevail in different types of muscle wasting. This is not unexpected, assuming that these pathways may serve to eliminate different classes of proteins. The lack of detectable activation of a given proteolytic system (eg, the $\mathrm{Ca}^{2+-d e p e n d e n t ~ p r o t e o l y t i c ~}$ process in fasted rats, Wing and Goldberg, 1993) or protease (eg, cathepsin D in septic rats, Voisin et al, 1994) in a given musclewasting condition is more intriguing. Several explanations may account for these observations. First, it has been suggested that the breakdown of myofibrillar and nonmyofibrillar proteins could be regulated independently (Lowell et al, 1986; Furuno et al, 1990; Wing and Goldberg, 1993). Second, the methods used to detect an activation of the different proteases may not be sensitive enough to detect small variations in proteolysis. Third, the breakdown rate of some classes of proteins may not be systematically increased in any catabolic state. Very different stimuli known to increase muscle proteolysis, for example, nutrient deprivation and disuse, may differentially affect the distribution pattern of individual muscle proteins.

Whether the ATP-ubiquitin-dependent proteolytic pathway may be functionally associated to the $\mathrm{Ca}^{2+}$-dependent or the lysosomal proteolytic system is still an open question. The former hypothesis is not supported by any experimental data. In addition, experiments in mdx mice did not support an alteration of the ATP-dependent proteolytic pathway (in accordance with the lack of loss of myofibrillar proteins), but clearly indicated a selective activation of $\mathrm{m}$ calpain (Combaret et al, 1994) consistent with $\mathrm{Ca}^{2+}$-stimulated proteolysis (Turner et al, 1988; MacLennan et al, 1991). By contrast, the lysosomal and the ATP-dependent proteolytic pathways could constitute a single entity. Gropper et al (1991) have shown that ubiquitinated proteins can be detected in the lysosome and that the ubiquitin-activating enzyme, $E_{1}$, was required for stress-induced lysosomal degradation of proteins. However, the presence of ubiquitin within lysosomes only appears to be relevant in neurodegenerative diseases (Mayer et al, 1991).

\section{CONCLUDING REMARKS}

In recent years, significant progress has been made in understanding the mechanisms that regulate ATP-ubiquitin-dependent proteolysis in skeletal muscle. However, these studies raise many questions. The precise identification of proteins that are ubiquitinated in skeletal muscle is of obvious importance. Equally important is the identification of signals in proteins that are involved in the selection of proteins for ubiquitin ligation and degradation. The significance of variations in mRNA levels for multiple components of the ATP-ubiquitindependent proteolytic pathway (and for 
cathepsins and calpains) in muscle atrophy must be elucidated. It is still totally unclear whether these variations reflect increased transcription, alterations in mRNA processing and transport, or in degradation rates. The role of hormones and specific nutrients (ie amino acids) in the activation and/or inactivation of the ubiquitin proteolytic pathway is also poorly defined. A final goal will be to examine whether mechanisms observed in animal models are active in cachectic patients. We have already started to explore this issue, and recently reported enhanced whole-body protein breakdown and 3methylhistidine urinary excretion in head trauma patients compared with healthy human volunteers (Mansoor et al, 1994). These variations were associated with increased mRNA levels for ubiquitin, $14 \mathrm{kDa}$ $E_{2}$, and $\mathrm{HC2}$ and $\mathrm{HC} 8$ proteasome subunits in muscle biopsies from head trauma patients (Vincent-Mansoor et al, 1994). Thus, the ATP-ubiquitin-dependent proteolytic pathway could play an important role in muscle wasting in some human diseases.

\section{ACKNOWLEDGMENTS}

This work was supported by grants from the Association française contre les myopathies, the Association pour la recherche sur le cancer, the conseil régional d'Auvergne, the French ministère des Affaires étrangères (Actions intégrées francoespagnoles 1991 and 1992) and ministère de I'Enseignement supérieur et de la Recherche, and the Institut national de la recherche agronomique.

\section{REFERENCES}

Attaix D (1993) Molecular biology of control of skeletal muscle proteolysis by nutrients. In: Abstracts of Educational Curriculum, Symposiums and Workshops of the 15th Congress on Clinical Nutrition and Metabolism. European Society for Enteral and Parenteral Nutrition, Budapest, Hungary, 187-189

Baracos VE, Rodemann HP, Dinarello CA, Goldberg $A L$ (1983) Stimulation of muscle protein degrada- tion and prostaglandin E2 release by leukocytic pyrogen (interleukin-1). N Engl J Med 308, 553-558

Baracos VE, DeVivo C, Goldberg AL (1992) Activation of different proteolytic systems in skeletal muscle of cachectic rats bearing Yoshida ascites hepatoma. In: Proceedings of the 9th ICOP Conference on Proteolysis and Protein turnover, Williamsburg, USA, Abstract 181

Barrett EJ, Gelfand RA (1989) The in vivo study of cardiac and skeletal muscle protein turnover. Diabetes Metab Rev 5, 133-148

Belkhou R, Béchet D, Cherel Y, Galluser M, Ferrara M, Le Maho $Y$ (1994) Effects of fasting and thyroidectomy on cysteine proteinase activities in liver and muscle. Biochim Biophys Acta 1199, 195-201

Chiang HL, Terlecky SR, Plant CP, Dice JF (1989) A role for a 70-kilodalton heat shock protein in lysosomal degradation of intracellular proteins. Science 246 , 382-385

Combaret L, Taillandier D, Aurousseau E et al (1994) Proteolytic pathways involved in muscular dystrophy in $\mathrm{mdx}$, dy/dy and mdf mice: a preliminary study. Reprod Nutr Develop 34, 636

Dardevet D, Sornet C, Taillandier D, Attaix D, Grizard J (1994) Gluctocorticoids do not regulate the ATP-ubiquitin-dependent proteolytic pathway in skeletal muscle of aged rats. In: Proceedings of the 10th ICOP Conference on Intracellular Protein Catabolism, Tokyo, Japan, in press

Driscoll J, Goldberg AL (1989) Skeletal muscle proteasome can degrade proteins in an ATP-dependent process that does not require ubiquitin. Proc Natl Acad Sci USA 86, 787-791

Fagan JM, Waxman L, Goldberg AL (1987) Skeletal muscle and liver contain a soluble ATP+ubiquitindependent proteolytic system. Biochem J 243, 335343

Fagan JM, Wajnberg EF, Culbert L, Waxman L (1992) ATP depletion stimulates calcium-dependent protein breakdown in chick skeletal muscle. Am J Physiol 262, E637-E643

Finley D, Chau C (1991) Ubiquitination. Annu Rev Cell Biol 7, 25-69

Flores EA, Bistrian BR, Pomposelli JJ, Dinarello CA, Blackburn GL, isttan NW (1989) Infusion of tumor necrosis factor/cachectin promotes muscle catabolism in the rat. A synergistic effect with interleukin 1. J Clin Invest 83, 1614-1622

Furuno K, Goodman MN, Goldberg AL (1990) Role of different proteolytic systems in the degradation of muscle proteins during denervation atrophy. $J$ Biol Chem $265,8550-8557$

Garcia-Martinez C, Agell N, Llovera M, Lopez-Soriano FJ, Argiles JP (1993) Tumour necrosis factor- $\alpha$ increases the ubiquitinization of rat skeletal muscle proteins. FEBS Lett 323, 211-214 
Goldberg AL (1992) The mechanism and functions of ATP-dependent proteases in bacterial and animal cells. Eur J Biochem 203, 9-23

Goldspink DF, Morton PAJ, Loughna P, Goldspink G (1986) The effect of hypokinesia and hypodynamia on protein turnover and the growth of four skeletal muscles of the rat. Pflügers Arch 407, 333-340

Goll DE, Thompson VF, Taylor RG, Zalewska T (1992) Is calpain activity regulated by membranes and autolysis or by calcium and calpastatin? Bioessays 14, 549-556

Gropper R, Brandt RA, Elias S et al (1991) The ubiquitin-activating enzyme, $E_{1}$, is required for stressinduced lysosomal degradation of cellular proteins. $J$ Biol Chem 266, 3602-3610

Haas AL, Riley DA (1988) The dynamics of ubiquitin pools within skeletal muscle. In: The Ubiquitin System (M Schlesinger, A Herskho, eds) Cold Spring Harbor Laboratory, New York, USA, 178-185

Hershko A, Ciechanover A (1992) The ubiquitin system for protein degradation. Annu Rev Biochem 61, 761807

Hoffman L, Pratt G, Rechsteiner M (1992) Multiple forms of the $20 \mathrm{~S}$ multicatalytic and the $26 \mathrm{~S}$ ubiquitin/ATPdependent proteases from rabbit reticulocyte lysate. J Biol Chem 267, 22362-22368

Ilian MA, Forsberg NE (1992) Gene expression of calpains and their specific endogenous inhibitor, calpastatin, in skeletal muscle of fed and fasted rabbits. Biochem J 287, 163-171

Jentsch $S$ (1992) The ubiquitin-conjugation system. Annu Rev Genet 26, 179-207

Johnson $P$ (1990) Calpains (intracellular calcium-activated cysteine proteinase): structure-activity relationships and involvement in normal and abnormal cellular metabolism. Int J Biochem 22, 811-822

Kettelhut IC, Wing SS, Goldberg AL (1988) Endocrine regulation of protein breakdown in skeletal muscle. Diabetes Metab Rev 4, 751-772

Li JB, Goldberg AL (1976) Effects of food deprivation on protein synthesis and degradation in rat skeletal muscles. Am J Physiol 231, 441-448

Li JB, Higgins JE, Jefferson LS (1979) Changes in protein turnover in skeletal muscle in response to fasting. Am J Physiol 236, E222-E228

Llovera M, Garcia-Martinez C, Agell N, Marzabal M, Lopez-Soriano FJ, Argiles JM (1994) Ubiquitin gene expression is increased in skeletal muscle of tumourbearing rats. FEBS Lett 338, 311-318

Lowell BB, Ruderman NB, Goodman MN (1986) Evidence that lysosomes are not involved in the degradation of myofibrillar proteins in rat skeletal muscle. Biochem J 234, 237-240

MacLennan PA, McArdle A, Edwards RT (1991) Effects of calcium on protein turnover of incubated muscles from mox mice. Am J Physio/ 260, E594-E598
Mansoor $\mathrm{O}$, Boirie $\mathrm{Y}$, Attaix $\mathrm{D}$, Schoeffler $\mathrm{P}$, Beaufrère $\mathrm{B}$ (1994) Protein metabolism in head trauma patients studied with $13 \mathrm{C}$ leucine. Clin Nutr 13, supp| 1 , abstract $p 13$

Mayer RJ, Lowe J, Landon M et al (1991) Ubiquitin and the lysosome system: Molecular immunopathology reveals the connection. Biomed Biochim Acta 50, 333-341

Medina R, Wing SS, Haas A, Goldberg AL (1991) Activation of the ubiquitin-ATP-dependent proteolytic system in skeletal muscle during fasting and denervation atrophy. Biomed Biochim Acta 50, 347-356

Medina R, Wing SS, Kettelhut I, Goldberg AL (1992) Regulation of different proteolytic systems in muscle by insulin and food intake. In: Protein Metabolism in Diabetes Mellitus (KS Nair, ed), Smith Gordon, London, UK, 111-123

Melloni E, Pontremoli S (1991) The calpain-calpastatin system: structural and functional properties. J Nutr Biochem 2, 467-476

Millward DJ, Bates PC, Grimble GK, Brown JG, Nathan M, Rennie MJ (1980) Quantitative importance of non-skeletal-muscle sources of $\mathrm{N}$-methylhistidine in urine. Biochem J 190, 225-228

Mitch WE, Medina R, Grieber S et al (1994) Metabolic acidosis stimulates muscle protein degradation by activating the adenosine triphosphate-dependent pathway involving ubiquitin and proteasomes. $J$ Clin Invest 93, 2127-2133

Mortimore GE, Kadowaki M, Heydrick SJ (1992) The autophagic pathway in liver: its regulation and role in macromolecular turnover. In: Protein Metabolism in Diabetes Mellitus (KS Nair, ed), Smith Gordon, London, UK, 125-138

Mykles DL, Haire MF (1991) Sodium dodecyl sulfate and heat induce two distinct forms of lobster muscle multicatalytic proteinase: the heat-activated form degrades myofibrillar proteins. Arch Biochem Biophys 288, 543-551

Nishimura $C$, Tamura T, Akioka $H$, Tokunaga F, Tanaka K, Ichihara A (1993) cDNA cloning of rat proteasome subunit RC10-II, assumed to be responsible for trypsin-like catalytic activity. FEBS Lett 336, 462466

Orlowski M (1990) The multicatalytic proteinase complex, a major extralysosomal proteolytic system. Biochemistry 29, 10289-10297

Pisters PWT, Brennan MF (1990) Amino-acid metabolism in human cancer cachexia. Annu Rev Nutr 10, 107-132

Rechsteiner M (1991) Natural substrates of the ubiquitin proteolytic pathway. Cel/ 66, 615-618

Rivett AJ (1993) Proteasomes: multicatalytic proteinase complexes. Biochem J 291, 1-10

Rogers S, Wells R, Rechsteiner M (1986) Amino-acids sequences common to rapidly degraded proteins: the PEST hypothesis. Science 234, 364-368 
Smith LK, Bradshaw M, Croall DE, Garner CW (1993) The insulin receptor substrate (IRS-1) is a PEST protein that is susceptible to calpain degradation in vitro. Biochim Biophys Res Comm 196, 767-772

Sorimachi H, Suzuki K (1992) Sequence comparison among muscle-specific calpain, p94, and calpain subunits. Biochim Biophys Acta 1160, 55-62

Sugden PH, Fuller SJ (1991) Regulation of protein turnover in skeletal and cardiac muscie. Biochem $J$ 273, 21-37

Taillandier D (1993) Régulation du métabolisme protéique musculaire chez le rat soumis à l'apesanteur simulée. Thèse de Docteur de l'Université BlaisePascal, Clermont-Ferrand II, France

Taillandier D, Aurousseau E, Obled A et al (1994) Coordinate activation of lysosomal, $\mathrm{Ca}^{2+-a n d ~ A T P-u b i-~}$ quitin-dependent proteolytic pathways in the soleus muscle of hindlimb suspended rats. Reprod Nutr Develop 34, 640

Tanaka K, li K, Ichihara A, Waxman L, Goldberg AL (1986) A high molecular weight protease in the cytosol of rat liver. I. Purification, enzymological properties and tissue distribution. J Biol Chem 261, 15197-15203

Tanaka K, Tamura T, Yoshimura T, Ichihara A (1992) Proteasomes: protein and gene structures. New Biol $4,173-187$

Tawa NE Jr, Goldberg AL (1994) Protein and aminoacid metabolism in muscle. In: Myology (AG Engel, C Franzini-Armstrong eds) Mc Graw-Hill Book Co, New York, NY, USA, in press

Tawa NE Jr, Kettelhut IC, Goldberg AL (1992) Dietary protein deficiency reduces lysosomal and nonlysosomal ATP-dependent proteolysis in muscle. Am J Physiol 263, E326-E334

Temparis S, Asensi M, Taillandier D et al (1994) Increased ATP-ubiquitin-dependent proteolysis in skeletal muscles of tumor-bearing rats. Cancer Res (in press)

Thomason DB, Booth FW (1990) Atrophy of the soleus muscle by hindlimb unweighting. J App/ Physiol 68, 1-12

Tischler M, Desautels M, Goldberg AL (1982) Does leucine, leucyltRNA or some metabolite of leucine regulate protein synthesis and degradation in skeletal and cardiac muscle? J Biol Chem 257, 16131621
Tischler ME, Rosenberg S, Satarug S et al (1990) Different mechanisms of increased proteolysis in atrophy induced by denervation or unweighting of rat soleus muscle. Metabolism 39, 756-763

Turner PR, Westwood T, Regen CM, Steinhardt RA (1988) Increased protein degradation results from elevated free calcium levels found from mdx mice. Nature (Lond) 335, 735-738

Varshavsky A (1992) The N-end rule. Cell 69, 725-735

Vincent-Mansoor O, Beaufrère B, Rallière $C$ et al (1994) Muscle wasting in head trauma patients results from a coordinate activation of lysosomal, $\mathrm{Ca}^{2+-}$ and ATPubiquitin-dependent proteolysis. In: Proceedings of the 10th ICOP Conference on Intracellular Protein Catabolism, Tokyo, Japan, in press

Voisin L, Taillandier D, Aurousseau E et al (1994) Involvement of $\mathrm{Ca}^{2+}$ - and ATP-ubiquitin-dependent proteases in increased skeletal muscle proteolysis in septic rats. Reprod Nutr Develop 34, 639-640

Wassner SJ, Li JB (1982) N-Methylhistidine release: Contributions of rat skeletal muscle, gastrointestinal tract and skin. Am J Physiol 243, E293-E297

Waterlow JC, Garlick PJ, Millward DJ (1978) Protein Turnover in Mammalian Tissues and in the Whole Body. Elsevier North Holland, Amsterdam, The Netherlands

Wing SS, Banville D (1992) Regulation of 14 kDa ubiquitin conjugating enzyme $\left(E_{2}\right)$ in rat muscle upon fasting and by insulin and IGF-1. In: Proceedings of the 9th ICOP Conference on Proteolysis and Protein turnover, Williamsburg, USA, Abstract 161

Wing SS, Goldberg AL (1993) Glucocorticoids activate the ATP-ubiquitin-dependent proteolytic system in skeletal muscle during fasting. Am J Physiol 264, E668-E676

Wing SS, Banville D (1994) 14-kDa ubiquitin-conjugating enzyme: structure of the rat gene and regulation upon fasting and by insulin. Am J Physiol 267, E39E48

Wing SS, Chiang AL, Goldberg AL, Dice JF (1991) Proteins containing peptide sequences related to lysphe-glu-arg-gln are selectively depleted in liver and heart but not skeletal muscle of fasted rats. Biochem J275, 165-169

Young VR, Munro HN (1978) N-Methylhistidine (3methylhistidine) and muscle protein turnover: an overview. Fed Proc 37, 2291-2300 